\title{
The Bodymind Model: A platform for studying the mechanisms of change induced by art therapy
}

\section{$\underline{\text { ABSTRACT }}$}

This paper introduces the Bodymind model of Art Therapy and delineates the processes through which it has salutary effects on individuals coping with a variety of health related challenges. The goal of this model is to articulate how activation, reorganization, growth and reintegration of the self can emerge from bodymind processes activated by art therapy. It provides a framework for the conduct of research that will test the key theoretical mechanisms through which art therapy benefits clients. We expect this model to be a spring board for discussion, debate and development of the profession of art therapy. Furthermore, we hope readers can use this model to conduct sound mechanistic studies. This paper can inform social scientists and medical professionals on the manner in which art making can contribute to health.

KEYWORDS: Body and Mind; Art based interventions; Art Therapy; Mechanistic studies

\section{Introduction}

Art Therapy is an integrative health profession that developed with influences from the fields of Psychiatry, Education and Art (Vick, 2003). As such, a sound theoretical foundation that is applicable to most practitioners is still developing. This paper draws on art therapy research and theoretical writing and offers a framework for understanding and testing of the mechanisms through which art therapy has its salutary effects. Elucidating the mechanisms of art therapy can define scope of practice, and assist non-art therapists to utilize the arts responsibly.

Empirical mechanistic research is defined as experimentation using an intervention to understand how or why change occurs. Mechanistic studies traditionally were designed to understand human biology (MacAllister \& Veighey, 2012), but have been expanded to psychology and the understanding of human behavior. Mechanistic research that is well designed can utilize social science theories to inform the medical field of ways in which social and emotional processes can be modified to improve health outcomes for patients.

There is a need to translate our theoretical and clinical knowledge about what is unique in art therapy and engage in the methodical study of these mechanisms. In this paper we fill a gap 
in the existing literature and delineate a model of the core processes, and mechanisms of art therapy and their effect on health. This conceptual model is designed to be practical, and facilitate the design of studies of the mechanisms of art therapy. Below we describe existing models that provide the foundation for this work.

The Expressive Therapies Continuum (ETC) (Kagin \& Lusebrink, 1978 \& Hinz, 2009) is a comprehensive and complex model that incorporates a developmental hierarchy in a continuum composed of three levels: 1) Kinesthetic/ Sensory, 2) Affective/ Perceptual \& 3) Cognitive/ Symbolic. The Creative axis can exist on all levels and is described as the joyful experience that accompanies imaginative processes. The ETC is inclusive of the divergent classic approaches, art as therapy and art psychotherapy, (Ulman, 2001). In this model, three important aspects of art therapy are not addressed: 1) the content of the art expression; 2) The context of the therapeutic relationship through which the art making was facilitated (beyond the provision of instructions); and 3) The physiological changes that occur during art making. Despite these limitations, the ETC model and Lusebrink's work has been fundamental in the understanding of the neurobiology of art therapy (Kapitan, 2014).

The art therapy relational neuroscience model (ATR-N) (Hass-Cohen \& Clyde Findlay, 2015) integrates relational neuroscience and interpersonal neurobiology with the practice of art therapy. In doing so, it takes in account some of the physiological processes which occur during art making and the triangular relationship between art therapist, client, and art making processes. The model postulates that novel sensory experiences, which occur during art making in the presence of an art therapist, can promote the emergence of an attuned, mindful, compassionate and integrated state of mind. The ATR-N model is very inclusive and provides the reader an opportunity to understand the developmental processes and the neurobiology behind what makes art therapy such a potent modality (Boehm, Cramer, Staroszynski, \& Ostermann, 2014). At the same time, the constructs are not operationalized in ways that make them accessible to scientific validation. The Body mind model informed by the ETC and the ATR-N and is designed to facilitate the empirical study of art therapy, by utilizing the standardized measurement of the mechanisms delineated in the appendix of this paper. 


\section{The Bodymind Model}

The purpose of this paper is twofold: 1) to describe a model that clearly articulates how reorganization, growth and reintegration of the self can emerge from body and mind processes activated by art therapy and 2) to provide a framework for the conduct of research that will test the key theoretical mechanisms through which art therapy benefits clients.

Many of our clients have experienced a major stressor, which could be in the form of developmental trauma or unfortunate life events that are experienced as traumatic. When an external event, such as a life threatening illness, occurs; confusion about oneself and one's life course is inherent and to be expected. This confusion opens an opportunity for reflection on the self that invites reorganization. The bodymind model is consistent with the non-Cartesian framework used in the ETC in which the mind and body are not viewed as separate and opposite entities. The main premise of this approach is that processes of the mind (thinking and feeling) are embedded in one's sensory and motor experiences. Winkielman, Niedenthal, Wielgosz, Eelen, \& Kavanagh (2015) provide an expanded description of the embodied perspective of cognition and emotion. The bodymind model is developmental and epigenetic in nature: each core therapeutic process evolves from those that precede it and earlier developmental processes are revisited in a cyclical manner. This epigenetic process of growth (Weihs \& Reiss, 1996; Wynne, 1988) can occur in every session as well throughout a whole course of treatment. Table 1 delineates this aspect of the model as well as the relationship between the four core therapeutic processes, and measurable mechanisms of art therapy.

The bodymind model fits within the framework of resource oriented models of therapeutic intervention (Priebe, Omer, Giacco, \& Slade, 2014). While we believe that art therapy is beneficial in helping individuals with deficits of many sorts, the bodymind model is designed to emphasize and tap in to individual's strengths and restore an embodied sense of self that is not necessarily related to illness or tragic life circumstances. The holistic and developmental aspects of the model are geared to emphasize that the body and mind operate as one and that art therapy operates in a dynamic epigenetic fashion. 


\section{Why bodymind?}

The tactile experience of art making induces body sensations and emotions. Thus we posit that art making with the support and guidance of an art therapist is a holistic bodymind process. Imagery is an inherent part of art therapy. In a laboratory study of information processing, using imagery increased emotionality ratings and positive affect as compared to verbal processing (Holmes, Mathews, Dalgleish, \& Mackintosh, 2006). Imagery evokes emotion via 3 pathways: 1) sensory stimulation of emotional systems in the brain; 2) responding to imagery as real emotion-arousing events; and 3) activating memories for emotional episodes in the past (Holmes \& Mathews, 2010). A recent review (Pearson, Naselaris, Holmes, \& Kosslyn, 2015) found similar activation from perceived and mental imagery.

A recent synthesis of current neuro-cognitive literature proposes that 3 interacting neural systems are engaged in the generation, perception and regulation of emotions (Smith \& Lane, 2015). According to this framework, we gain access to our emotions through a process that is interoceptive (relating to stimuli that arise within the body) or somatosensory (information that is perceived through touch, pain, temperature and body position and muscle length and tension) which is then "translated" to have emotional meaning. This is especially pertinent for art therapy, as the engagement with art materials along with the concrete visual imagery may allow for easier access to emotional material than verbal communication alone. Current neuroscientific evidence reveals brain based mechanisms of emotion appraisal, through which interoceptive and somatosensory processes of emotion are appraised for meaning (Brosch \& Sander, 2013).

Art-making is a sensory experience. The experience of touching and manipulating art materials activates sensory responses to pressure, vibration and temperature. The haptic sense helps an individual understand an object's qualities such as its shape, weight and texture through sensations experienced in the joints and muscles while manipulating the object and moving the skin over it. The amygdala becomes activated through the in pour of sensory information via the somatosensory primary cortex and thus this becomes an emotional experience as well, even before meaning is made (LeDoux, 2000; Lusebrink, 2004; Smith \& Lane, 2015).

The experience of pleasure is universally connected to sensory experiences (BiswasDiener et al., 2014). The pleasurable aspect of the sensory interaction with art materials may make difficult content tolerable. As such, we can hypothesize that art making may assist 
individuals coping with a negative emotional experience in becoming less fearful of engaging with emotional content and thus increasing both their emotional awareness and acceptance. Increased awareness and acceptance of emotions has been found to have a relationship with psychological and physical health (Lane \& Schwartz, 1987; Politi, Enright, \& Weihs, 2007).

The tactile experience of engaging with art materials is arousing and requires sustained attention. The pleasurable aspects of tactile engagement (as mentioned above) within the framework of a supportive relationship provide the opportunity for well-balanced arousal accompanied by a sense of security and relaxation. This is integral to the health benefits of art therapy as it enables the processing of difficult content without the harming effect of initiating the cascade of the survival system. This activation results in the release of hormones that are part of the systems in charge of maintaining allostasis (McEwen \& Seeman, 1999). The sustained relaxation enables the emotional and cognitive processing that is necessary for change to occur in psychotherapy (Lane, 2008; Lane et al., 2015; Thayer \& Lane, 2000).

Visual processing plays an important role in assessing our environment, and has been shown to be modulated by emotion and attention (Lane, Chua, \& Dolan, 1999). Emotional arousal recruits our attention to motivational cues for survival from the environment. The behavioral manifestation of motivation includes approach toward desired outcomes and avoidance of undesired outcomes. Approach/avoidance motivation includes both anticipatory and exploratory search phases which are then guided by incentives that can be innate or conditioned emotional stimuli (LeDoux, 2012).

\section{Four core therapeutic processes:}

The following section provides a general depiction of the 4 core therapeutic processes of art therapy according to the bodymind model. In the appendix you will find a detailed description of each of the mechansims. Table 1 delineates the 4 processes and how the mechanisms related to each process. In addition, each mechanism is accompanied by a suggested validated measure that can be used in art therapy research.

1. The triangular relationship between the art therapist, the art process and the art product, facilitates secure attachment in a unique manner that mimics primary relationships. Clients are greeted by a supportive individual (the art therapist), who has organized a safe and aesthetic 
environment for exploration. The art materials that are offered can be seen metaphorically and concretely as nurturing, metaphorically, the art therapy room can be experienced as womb-like, the art materials as food-like nurturance (Moon, 2011). Furthermore, the relationship of the client with the art materials is postulated to enable the expression of negative emotions through art making, enabling a unique working relationship between the client and therapist to develop (Hilbuch, Snir, Regev, \& Orkibi, 2016). Thus, the triangular relationship between clienttherapist- art process and product can be experienced as primary (Hass-Cohen \& Clyde Findlay, 2015). To facilitate this process the art therapist also has a concrete role in ensuring that each client has the materials needed, that the room is adequately lighted and is at comfortable temperature.

Clients are encouraged to explore the art therapy environment while art therapists observe, making themselves available as attachment figures not unlike a good-enough mother providing a safe base for a toddler to return to as he goes out to explore his surroundings (Bowlby, 1988). The physicality of the engagement with the art materials, the activation of the senses and the movement that occurs while engaging in art making, triggers the engagement of both Body and Mind aspects of the self. When this activation occurs in the presence of an attachment figure, clients have the opportunity to repair attachment issues that may arise through the relationship with the therapist, the art materials, the art making process and the art product. This work may continue should the client engage in art making after therapy concludes.

2. Self-Engagement. Self-Engagement with balanced arousal and attention occurs within the framework of the supportive triangular relationship and the safety of the transitional space created for art making. Qualitative research of art therapy interventions supports the notion that even when expressing content with negative context, the overall experience remains a positive one, leaving the art makers with a sense of relief (Collie, Bottorff, \& Long, 2006). We believe that the soothing and nurturing quality of the art materials along with the safety and support provided by the art therapist and the attention and motivation required to sustain the activity enable an individual engaged in art making to remain motivated and aroused without the sense of threat to survival. This self-engagement is a result of an integration of the body and mind processes as described in the previous sections. This is potentially unique to the creative arts 
therapies, or at least is differentiated from processes that occur through verbal psychotherapy alone.

\section{Embodied Self-Expression through Transition from Implicit to Explicit Processing}

Art making provides an opportunity to express somatic knowledge that is not easily translatable into words. Externalization of this knowledge via the art making process and through reflection on the art product facilitates the use language to express the previously inexpressible somato-emotional knowledge. Thus, art making provides an excellent opportunity for developmental progression and integration through the translation of emotional material from implicit to explicit representations.

The processing of emotion is learned developmentally and involves the cognitive process of transforming implicit (somatic) emotion representations into explicit (pictorial/ verbal) representations (Subic-Wrana, Beutel, Garfield, \& Lane, 2011). Implicit emotion representations are experienced as physical sensations, are unconscious and inform the self automatically without reflection or metacognition. Explicit emotion representations are conscious and communicable via words. The ability to verbalize emotions requires one to recognize a sensation as an emotion and then translate that sensation into symbolic form as pictures or words. The verbal or symbolic expression of thoughts develops from undifferentiated to differentiated and is integrated (Subic-Wrana et al., 2011). Art making is here seen as an intermediate step that facilitates the externalization of somatic knowledge. At times the pictorial form will suffice (as in the case of Art as Therapy (Kramer, 2001)) and at other times verbal discussion will ensue as in Art Psychotherapy (Naumburg, 1955).

4. Meta-cognitive processes. Once a safe enough attachment relationship is formed, the client engages with the art materials with relaxed exploratory arousal and is able to use the art making process for self-expression and for the transition of emotional material from implicit to explicit arenas. In this context, the art therapist can facilitate the engagement in reflective or perspective taking processes, or more broadly, metacognition. Metacognition is the ability to evaluate your own thinking or thinking about thinking (Flavell, 1979). The implicit form of metacognitive processes is automatic and occurs without much conscious thought. It is the type of automatic assessment we make when we are making a survival type assessment of our environment. The explicit metacognition is reflective and occurs after an assessment of our mental contents. This 
enables us to examine our behavior, feelings and thinking and provide a justification (Frith, 2012). The limits of introspection through verbal access have long been recognized (Nisbett \& Wilson, 1977), thus making the use of art an important intermediate step from implicit to explicit processing. Laboratory studies that look at external versus internal feedback processes and verbal versus visual processing have supported this notion (Berry \& Broadbent, 1984, Schooler, 2002). Mentalization is a specific form of metacognition and refers to competencies that enable humans to infer and think about the mental states of self and others (Liotti \& Gilbert, 2011). The ability to engage in metacognitive processes, such as mentalization is limited through verbal means and impaired when one’s sense of attachment is threatened (Fonagy, Bateman, \& Bateman, 2011; Fonagy, Gergely, \& Jurist, 2004).In addition to a sense of safety, along with relaxed and open attention, it is inherently important to have exploratory motivation in order to engage in and develop metacognitive abilities. The opportunity to externalize emotional and cognitive material in a concrete form and then take time to engage in a reflective process provides the opportunity for both perspective taking and meaning making.

\section{Summary}

This paper provides an explanatory framework of the ways in which art therapy benefits clients. The model has deep roots in psychoanalytic theory and theories of attachment which are foundational for the profession of art therapy (Kramer, 2001). This model incorporates the relational aspects of art therapy (Malchiodi, 2011) as well as the somatic, emotional, cognitive and behavioral effects of art making in this framework (Czamanski-Cohen et al., 2014).

Art therapists, medical professionals and psychotherapists who use art can use this model to learn more about the work they do, as well as to design and implement studies that will provide us with necessary empirical knowledge regarding the mechanisms through which art therapy has its salutary effects. A better understanding of the mechanisms of art therapy will improve art therapist's ability communicate with other team members, colleagues and administrators about the work they do. We believe that an improved ability to understand the mechanisms of art therapy will provide art therapists the opportunity to offer care that is tailored to each client's needs. This model is not all encompassing nor do we believe that it is feasible to examine all mechanisms in one study. We would like this to be the beginning of a discussion and a work in progress. We invite other researchers to test some of the proposed mechanisms in the 
field in order to continue to demonstrate and further elucidate the clinical knowledge that we have been passionately collecting for the past 80 years.

\section{References}

Allen, J. G. (2012). Restoring mentalizing in attachment relationships: Treating trauma with plain old therapy. Arlington, VA : American Psychiatric Association.

Babyak, M. A., Snyder, C., \& Yoshinobu, L. (1993). Psychometric properties of the Hope Scale: A confirmatory factor analysis. Journal of Research in Personality, 27(2), 154-169.

Bandler, R., \& Grinder, J. (1982). Reframing: NLP and the transformation of meaning: Moab, UT: Real People Press.

Bandura, A. (1982). Self-efficacy mechanism in human agency. American psychologist, 37(2), 122.

Bateman, A. W., \& Fonagy, P. (2004). Mentalization-based treatment of BPD. Journal of personality disorders, 18(1), 36-51.

Berry, D. C., \& Broadbent, D. E. (1984). On the relationship between task performance and associated verbalizable knowledge. The Quarterly Journal of Experimental Psychology, 36(2), 209-231.

Biswas-Diener, R., Linley, P. A., Dovey, H., Maltby, J., Hurling, R., Wilkinson, J., \& Lyubchik, N. (2014). Pleasure: An Initial Exploration. Journal of Happiness Studies, 1-20.

Boehm, K., Cramer, H., Staroszynski, T., \& Ostermann, T. (2014). Arts therapies for anxiety, depression, and quality of life in breast cancer patients: a systematic review and metaanalysis. Evidence Based Complementary and Alternative Medicine, 103297, 1-9. doi:10.1155/2014/103297

Bond, F. W., Hayes, S. C., Baer, R. A., Carpenter, K. M., Guenole, N., Orcutt, H. K., . . . Zettle, R. D. (2011). Preliminary psychometric properties of the Acceptance and Action Questionnaire-II: A revised measure of psychological inflexibility and experiential avoidance. Behavior Therapy, 42(4), 676-688. 
Bower, J. E. (2014). Cancer-related fatigue mechanisms, risk factors, and treatments. Nature Reviews Clinical Oncology, 11(10), 597-609.

Bowlby, J. (1988). Attachment, communication, and the therapeutic process. A secure base: Parent-child attachment and healthy human development, 137-157.

Bradley, M. M., \& Lang, P. J. (1994). Measuring emotion: the self-assessment manikin and the semantic differential. Journal of behavior therapy and experimental psychiatry, 25(1), 49-59.

Brewer, J. A., Sinha, R., Chen, J. A., Michalsen, R. N., Babuscio, T. A., Nich, C., ... \& Rounsaville, B. J. (2009). Mindfulness training and stress reactivity in substance abuse: Results from a randomized, controlled stage I pilot study.Substance Abuse, 30(4), 306317.

Brosch, T., \& Sander, D. (2013). Comment: the appraising brain: towards a neuro-cognitive model of appraisal processes in emotion. Emotion Review,5(2), 163-168.

Carlson, L. E., \& Brown, K. W. (2005). Validation of the Mindful Attention Awareness Scale in a cancer population. Journal of psychosomatic research, 58(1), 29-33.

Casellas-Grau, A., Font, A., \& Vives, J. (2014). Positive psychology interventions in breast cancer. A systematic review. Psycho-Oncology, 23(1), 9-19.

Chilton, G. (2013). Art therapy and flow: A review of the literature and applications. Art Therapy, 30(2), 64-70.

Collie, K., Bottorff, J. L., \& Long, B. C. (2006). A narrative view of art therapy and art making by women with breast cancer. J Health Psychol, 11(5), 761-775.

Craske, M. G., Lang, A. J., Aikins, D., \& Mystkowski, J. L. (2006). Cognitive behavioral therapy for nocturnal panic. Behavior Therapy, 36(1), 43-54.

Crosswell, A. D., Lockwood, K. G., Ganz, P. A., \& Bower, J. E. (2014). Low heart rate variability and cancer-related fatigue in breast cancer survivors. Psychoneuroendocrinology, 45, 58-66.

Csikszentmihalyi, M. (1997). Finding flow: New York: Basic Books.

Czamanski-Cohen, J. (2012). The use of art in the medical decision-making process of oncology patients. Art Therapy, 29(2), 60-67.

Czamanski-Cohen, J., Sarid, O., Huss, E., Ifergane, A., Niego, L., \& Cwikel, J. (2014). CBART-The use of a hybrid cognitive behavioral and art based protocol for treating pain 
and symptoms accompanying coping with chronic illness. The Arts in Psychotherapy, 41(4), 320-328.

Damen, T. G., Dijksterhuis, A., \& van Baaren, R. B. (2014). On the Other Hand Nondominant Hand Use Increases Sense of Agency. Social Psychological and Personality Science, 1948550614527626.

Davies, C. D., Niles, A. N., Pittig, A., Arch, J. J., \& Craske, M. G. (2015). Physiological and behavioral indices of emotion dysregulation as predictors of outcome from cognitive behavioral therapy and acceptance and commitment therapy for anxiety. Journal of behavior therapy and experimental psychiatry,46, 35-43.

DeCristofaro, S. (2007). The inspiring and regenerative power of the arts. Clinical Nurse Specialist, 21(3), 170-171. doi:10.1097/01.NUR.0000270012.51716.2c

Devlin, B. (2006). The art of healing and knowing in cancer and palliative care. Int J Palliat Nurs, 12(1), 16-19.

Dinarello, C.A. (2000). Proinflammatory Cytokines, Chest, 118(2), 503-508.

Eriksson, M., \& Lindström, B. (2006). Antonovsky’s sense of coherence scale and the relation with health: a systematic review. Journal of epidemiology and community health, 60(5), 376-381.

Falkenström, F., Hatcher, R. L., \& Holmqvist, R. (2015). Confirmatory Factor Analysis of the Patient Version of the Working Alliance Inventory-Short Form Revised. Assessment, 22(5), 581-593.

Fegg, M. J., Kramer, M., Bausewein, C., \& Borasio, G. D. (2007). Meaning in life in the Federal Republic of Germany: results of a representative survey with the Schedule for Meaning in Life Evaluation (SMiLE). Health and quality of life outcomes, 5(1), 1.

Feldman, G., Greeson, J., \& Senville, J. (2010). Differential effects of mindful breathing, progressive muscle relaxation, and loving-kindness meditation on decentering and negative reactions to repetitive thoughts. Behav Res Ther, 48(10), 1002-1011. doi:10.1016/j.brat.2010.06.006

Flavell, J. H. (1979). Metacognition and cognitive monitoring: A new area of cognitivedevelopmental inquiry. American psychologist, 34(10), 906.

Fonagy, P., \& Bateman, A. W. (2006). Mechanisms of change in mentalization-based treatment of BPD. Journal of clinical psychology, 62(4), 411-430. 
Fonagy, P., Bateman, A., \& Bateman, A. (2011). The widening scope of mentalizing: A discussion. Psychology and Psychotherapy: Theory, Research and Practice, 84(1), 98110.

Fonagy, P., Gergely, G., \& Jurist, E. L. (2004). Affect regulation, mentalization and the development of the self: London: Karnac books.

Fonagy, P., Luyten, P., Moulton-Perkins, A., Lee, Y.-W., Warren, F., Howard, S., . . Lowyck, B. (2016). Development and validation of a self-report measure of mentalizing: the Reflective Functioning Questionnaire. PloS One, 11(7), e0158678.

Forzoni, S., Perez, M., Martignetti, A., \& Crispino, S. (2010). Art therapy with cancer patients during chemotherapy sessions: An analysis of the patients' perception of helpfulness. Palliative and Supportive Care, 8(01), 41-48.

Fresco, D. M., Moore, M. T., van Dulmen, M. H., Segal, Z. V., Ma, S. H., Teasdale, J. D., \& Williams, J. M. G. (2007). Initial psychometric properties of the experiences questionnaire: validation of a self-report measure of decentering. Behavior Therapy, 38(3), 234-246.

Frith, C. D. (2012). The role of metacognition in human social interactions. Philosophical Transactions of the Royal Society B: Biological Sciences, 367(1599), 2213-2223.

Fritsche, J. (2014). Mind-Body awareness in art therapy with chronic pain syndrome. In L. Rappaport (Ed.), Mindfulness and the Arts Therapies (pp. 81-94). London: Jessica Kingsley Publishers.

Garakani, A., Martinez, J. M., Aaronson, C. J., Voustianiouk, A., Kaufmann, H., \& Gorman, J. M. (2009). Effect of medication and psychotherapy on heart rate variability in panic disorder. Depression and Anxiety, 26(3), 251-258.

Gendlin, E. T. (1962). Experiencing and the creation of meaning: New York: Free press of Glencoe.

Gross, J. J., \& John, O. P. (2003). Individual differences in two emotion regulation processes: implications for affect, relationships, and well-being. Journal of personality and social psychology, 85(2), 348.

Gross, J. J. (2011). Handbook of emotion regulation. New York: Guilford Press.

Gross, J. J. (2015). Emotion regulation: Current status and future prospects. Psychological Inquiry, 26(1), 1-26. 
Hansen, A. L., Kvale, G., Stubhaug, B., \& Thayer, J. F. (2013). Heart Rate Variability and Fatigue in Patients With Chronic Fatigue Syndrome After a Comprehensive Cognitive Behavior Group Therapy Program. Journal of Psychophysiology. 27(2), 67-75.

Hass-Cohen, N., \& Clyde Findlay, J. (2015). Art Therapy and the Neuroscience of Relationships, Creativity, and Resiliency. New York: W. W. Norton \& Company.

Hatcher, R. L., \& Gillaspy, J. A. (2006). Development and validation of a revised short version of the Working Alliance Inventory. Psychotherapy Research, 16(1), 12-25.

Hilbuch, A., Snir, S., Regev, D., \& Orkibi, H. (2016). The role of art materials in the transferential relationship: Art psychotherapists’ perspective. The Arts in Psychotherapy, 49, 19-26.

Hinz, L. D. (2009). Expressive therapies continuum: A framework for using art in therapy: Routledge.

Holmes, E. A., Mathews, A., Dalgleish, T., \& Mackintosh, B. (2006). Positive interpretation training: effects of mental imagery versus verbal training on positive mood. Behavior Therapy, 37(3), 237-247. doi:10.1016/j.beth.2006.02.002

Holmes, E. A., \& Mathews, A. (2010). Mental imagery in emotion and emotional disorders. Clinical Psychology Review, 30(3), 349-362. doi:10.1016/j.cpr.2010.01.001

Jackson, S. A., \& Marsh, H. W. (1996). Development and validation of a scale to measure optimal experience: The Flow State Scale. Journal of sport and exercise psychology, 18, 17-35.

Kagin, S. L., \& Lusebrink, V. B. (1978). The expressive therapies continuum. Art Psychotherapy, 5(4), 171-180.

Kapitan, L. (2014). Introduction to the Neurobiology of Art Therapy: Evidence Based, Complex, and Influential. Art Therapy, 31(2), 50-51.

Kashdan, T. B., \& Rottenberg, J. (2010). Psychological flexibility as a fundamental aspect of health. Clinical psychology review, 30(7), 865-878.

Klein, M. H., Mathieu-Coughlan, P., \& Kiesler, D. J. (1986). The experiencing scales. The psychotherapeutic process: A research handbook, 21, 71.

Koole, S. L. (2009). The psychology of emotion regulation: An integrative review. Cognition and Emotion, 23(1), 4-41.

Kramer, E. (2001). Art as therapy: Collected papers. New York: Jessica Kingsley Publishers. 
Kuppens, P., Tuerlinckx, F., Russell, J. A., \& Barrett, L. F. (2013). The relation between valence and arousal in subjective experience. Psychological Bulletin, 139(4), 917.

Lane, R. D. (2006). Theory of emotional awareness and brain processing of emotion. International Congress Series, 1287, 116-121.

Lane, R. D. (2008). Neural substrates of implicit and explicit emotional processes: a unifying framework for psychosomatic medicine. Psychosomatic medicine, 70(2), 214-231.

Lane, R. D., Chua, P. M., \& Dolan, R. J. (1999). Common effects of emotional valence, arousal and attention on neural activation during visual processing of pictures. Neuropsychologia, 37(9), 989-997.

Lane, R. D., \& Schwartz, G. E. (1987). Levels of emotional awareness: A cognitivedevelopmental theory and its application to psychopathology. The American journal of psychiatry, 144, 133-143.

Lane, R. D., Quinlan, D. M., Schwartz, G. E., Walker, P. A., \& Zeitlin, S. B. (1990). The Levels of Emotional Awareness Scale: A cognitive-developmental measure of emotion. Journal of personality assessment, 55(1-2), 124-134.

Lane, R. D., Weihs, K. L., Herring, A., Hishaw, A., \& Smith, R. (2015). Affective Agnosia: Expansion of the Alexithymia Construct and a New Opportunity to Integrate and Extend Freud's Legacy. Neuroscience \& Biobehavioral Reviews, 55, 594-611.

LeDoux, J. (2000). Emotion circuits in the brain. Annual Reviews of Neuroscience, 23, 155-184. doi:10.1146/annurev.neuro.23.1.155

LeDoux, J. (2012). Rethinking the emotional brain. Neuron, 73(4), 653-676.

Lee, V., Cohen, S. R., Edgar, L., Laizner, A. M., \& Gagnon, A. J. (2006). Meaning-making intervention during breast or colorectal cancer treatment improves self-esteem, optimism, and self-efficacy. Social science \& medicine, 62(12), 3133-3145.

Liotti, G., \& Gilbert, P. (2011). Mentalizing, motivation, and social mentalities: Theoretical considerations and implications for psychotherapy. Psychology and Psychotherapy: Theory, Research and Practice, 84(1), 9-25.

Lipson, E. J. (2011). Art in oncology: how patients add life to their days. Journal of Clinical Oncology, 29(10), 1392-1393. doi:10.1200/jco.2010.33.9168

Lusebrink, V. B. (2004). Art therapy and the brain: An attempt to understand the underlying processes of art expression in therapy. Art Therapy, 21(3), 125-135. 
Lusebrink, V. (2014). Art Therapy and the Neural Basis of Imagery: Another Possible View. Art Therapy, 31(2), 87-90.

MacAllister, R., \& Veighey, K. (2012). Governing mechanistic studies to understand human biology. Research Ethics, 8(4), 212-215. doi:10.1177/1747016112464840

Malchiodi, C. A. (2011). Handbook of art therapy. New York: Guilford Press.

McEwen, B. S., \& Seeman, T. (1999). Protective and damaging effects of mediators of stress: elaborating and testing the concepts of allostasis and allostatic load. Annals of the New York Academy of Sciences, 896(1), 30-47.

Moon, C. H. (2011). Materials and media in art therapy: Critical understandings of diverse artistic vocabularies. New York: Routledge.

Naumburg, M. (1955). Art as Symbolic Speech. The Journal of Aesthetics and Art Criticism, 13(4), 435-450. doi:10.2307/426931

Nisbett, R. E., \& Wilson, T. D. (1977). Telling more than we can know: verbal reports on mental processes. Psychological review, 84(3), 231.

Nolen-Hoeksema, S., Wisco, B. E., \& Lyubomirsky, S. (2008). Rethinking rumination. Perspectives on psychological science, 3(5), 400-424.

Pearson, J., Naselaris, T., Holmes, E. A., \& Kosslyn, S. M. (2015). Mental Imagery: Functional Mechanisms and Clinical Applications. Trends in Cognitive Sciences, 19(10), 590-602.

Politi, M. C., Enright, T. M., \& Weihs, K. L. (2007). The effects of age and emotional acceptance on distress among breast cancer patients. Support Care Cancer, 15(1), 73-79. doi:10.1007/s00520-006-0098-6

Priebe, S., Omer, S., Giacco, D., \& Slade, M. (2014). Resource-oriented therapeutic models in psychiatry: conceptual review. Br J Psychiatry, 204, 256-261. doi:10.1192/bjp.bp.113.135038

Sarenmalm, E. K., Browall, M., Persson, L. O., Fall-Dickson, J., \& Gaston-Johansson, F. (2013). Relationship of sense of coherence to stressful events, coping strategies, health status, and quality of life in women with breast cancer. Psycho-Oncology, 22(1), 20-27.

Schaverien, J. (1987). The scapegoat and the talisman: Transference in art therapy. In Dalley, T., Case, C., Schaverien, J., Weir, F. Halliday, D. Hall, P.W. \& Waller, D. (Eds.). Images of art therapy: New developments-theory and practice New York: Tavistock Publications, 88-127. 
Schooler, J. W. (2002). Verbalization produces a transfer inappropriate processing shift. Applied Cognitive Psychology, 16(8), 989-997.

Shor, V., Grinstein-Cohen, O., Reinshtein, J., Liberman, O., \& Delbar, V. (2014). Health-related quality of life and sense of coherence among partners of women with breast cancer in Israel. European Journal of Oncology Nursing. 19(1), 18-22.

Smith, R., \& Lane, R. D. (2015). The neural basis of one's own conscious and unconscious emotional states. Neuroscience \& Biobehavioral Reviews, 57, 1-29.

Snyder, C. R. (1995). Conceptualizing, measuring, and nurturing hope. Journal of Counseling and Development: JCD, 73(3), 355.

Springham, N., Findlay, D., Woods, A., \& Harris, J. (2012). How can art therapy contribute to mentalization in borderline personality disorder? International Journal of Art Therapy, 17(3), 115-129.

Subic-Wrana, C., Bruder, S., Thomas, W., Lane, R. D., \& Köhle, K. (2005). Emotional awareness deficits in inpatients of a psychosomatic ward: a comparison of two different measures of alexithymia. Psychosomatic Medicine, 67(3), 483-489.

Subic-Wrana, C., Beutel, M. E., Garfield, D. A., \& Lane, R. D. (2011). Levels of emotional awareness: A model for conceptualizing and measuring emotion-centered structural change. The International Journal of Psychoanalysis, 92(2), 289-310.

Thayer, J. F., \& Lane, R. D. (2000). A model of neurovisceral integration in emotion regulation and dysregulation. Journal of affective disorders, 61(3), 201-216.

Tsai, J. L., Knutson, B., \& Fung, H. H. (2006). Cultural variation in affect valuation. Journal of personality and social psychology, 90(2), 288.

Ulman, E. (2001). Art therapy: Problems of definition. American Journal of Art Therapy, 40(1), 16.

Vick, R. M. (2003). A brief history of art therapy. Handbook of art therapy, New York: Guilford Press, 5-15.

Weihs, K., \& Reiss, D. (1996). Family reorganization in response to cancer: A developmental perspective. In: Baider, L., Cooper, C. L., Kaplan De-Nour, A. (Eds.) Oxford, England: John Wiley \& Sons, 3-29. 
Weihs, K. L., Enright, T. M., \& Simmens, S. J. (2008). Close relationships and emotional processing predict decreased mortality in women with breast cancer: preliminary evidence. Psychosom Med, 70(1), 117-124. doi:10.1097/PSY.0b013e31815c25cf

Wells, A., \& Matthews, G. (2014). Attention and Emotion: A Clinical Perspective. New York: Psychology Press Routledge Classic Edition.

Winger, J. G., Adams, R. N., \& Mosher, C. E. (2015). Relations of meaning in life and sense of coherence to distress in cancer patients: a meta-analysis. Psycho-Oncology, 25(1), 2-10.

Wynne, L. C. (1988). An epigenetic model of family processes. In Falicov, J. (Ed.) Family Transitions: Continuity and Changes over the Lifespan. New York: Guilford press, pp.81106. 


\section{Appendix- Specific measures for the mechanisms in the Bodymind model of art therapy}

In the following section we breakdown the overarching core processes into processes that can be measured either by standardized questionnaires or directly, as in the case of the physiological mechanisms. This list is not intended to be exhaustive, and additional mechanisms may be added without affecting the framework of the bodymind model. Conducting empirical studies in clinical or laboratory settings with well-designed controls will enable us to determine the mechanisms of art therapy.

1. Tactile engagement. Before meaning making through art there is a bilateral engagement between the patient and the art materials. This exploratory stage is pre-symbolic and exploratory and occurs primarily, but not only in the bodily sphere. This mechanism correlates well with the sensory/kinesthetic stage of the ETC (V. Lusebrink, 2014; V. B. Lusebrink, 2004). While tactile engagement can be observed and recorded behaviorally, we are unaware of a validated measure of engagement. In lieu of this, we offer to use the Self-Assessment manikin (SAM), specifically we can focus on the dominance sub-scale which measures the potency of the experience (Bradley \& Lang, 1994). In addition we offer 2 related physiological measures that are indicators of arousal.

a. Heart Rate Variability (HRV): Arousal and relaxation can be measured with HRV, which is a measure of beat-to-beat temporal changes in heart rate and these changes reflect the output of the central autonomic network. The vagus nerve is a central component of the autonomic network, connecting the brain to the body. Through the vagus nerve, the parasympathetic nervous system regulates metabolic output in response to environmental stimuli and enables social engagement (Porges, 2007). The parasympathetic nervous system (PNS) inhibits the sinoatrial (SA) node and slows heart rate, while the sympathetic nervous system (SNS) excites the cardiac muscle increasing contractility (Kemp \& Quintana, 2013). Heart rate increases on inspiration and decreases on. Respiratory sinus arrhythmia (RSA) is a rhythmical fluctuation in the heart's beat-to-beat intervals that occur with the process of respiration, which is characterized by a shortening and lengthening of heart periods in a phase relationship with inspiration and expiration (Berntson, Cacioppo, \& Quigley, 1993). In this manner we can assess RSA as an index of PNS activity. 
We expect to find that art therapy enhances HRV through the influence of the prefrontal cortex to modulate emotional arousal and facilitate mentalization. Mentalization requires prefrontal cortical function, which is impaired in the context of high emotional arousal (SNS). As activity in the prefrontal cortex increases parasympathetic tone as indexed by heart rate variability (HRV), increases (Lane, 2006; Lane et al., 2009; Thayer \& Lane, 2000). As clients engage in art activities, have tactile experiences and achieve a general sense of safety in the triangular relationship their bodies relax. This is expected to increase HRV through influences of somatic relaxation on parasympathetic nervous system activity and through influences stemming from the support from the therapeutic relationship and positive cognitions derived from the sense of accomplishment and agency related to authentic self-expression and mastery that may lead to increased parasympathetic activity. Several studies demonstrate the potential of psychotherapeutic interventions, such as cognitive behavioral interventions and mindfulness training to change resting and responsive HRV (Craske, Lang, Aikins \& Mystkowski, 2006; Brewer et al, 2009; Garakani et al, 2009; Davies, Niles, Pittig, Arch \& Craske, 2015; Hansen, Kvale, Stubhaug \& Thayer, 2015).

b. Inflammation: Cytokines are small, nonstructural proteins that are regulators of host responses to infection, immune responses, inflammation, and trauma (Dinarello, 2000). There are several psychological, behavioral and biological risk factors can influence cytokine proliferation and thus inflammation (Bower, 2014). Inflammation has been shown to be related to low HRV (Crosswell, Lockwood, Ganz \& Bower, 2014 \& Bower, 2014). We expect that art therapy interventions will increase participant's resting and responsive HRV that will mediate decreases in proinflammatory cytokines and that this reduction in inflammation will mediate reductions in depression, anxiety, pain and fatigue (Thayer \& Sternberg, 2006).

2. Increasing levels of emotion awareness. Individuals differ in their sensitivity to and the valence of their emotional response to internal and external situations (Gross, 2015; Koole, 2009). In order to be open and accepting of emotional experiences, one needs to be aware of emotions. Awareness of emotions is a continuum and individuals differ in their abilities and the complexity of their awareness (Subic-Wrana, Beutel, Garfield \& Lane, 2011). The model of levels of emotion awareness is a cognitive developmental model positing that cognitive development occurs when knowledge is transferred from an implicit pattern, which involves 
sensorimotor or bodily information to patterns of explicit thought (Lane, 2006; Lane \& Schwartz, 1987; Lane, Weihs, Herring, Hishaw, \& Smith, 2015) that include conscious processing through language or other symbolic formations, such as visual art.

The act of creating an image and the process of externalizing internal emotional material can assist individuals in increasing emotion awareness. The use of lines, colors, shapes along with symbols and metaphors ease the access to preverbal material that may not be easily accessible through words. The way language and art are used can modify what one knows about emotion and how emotion is experienced. Art can be an effective way to examine implicit expression. Support from a trained art therapist can help individuals articulate and know what they are feeling and why (Lane et al., 2015; Subic-Wrana, Bruder, Thomas, Lane, \& Köhle, 2005). Art may prevent or remediate such regression through the movement of emotional content from the implicit to explicit arenas. The art making process lends itself to paying attention and acceptingly exploring sensations as they arise in the body. It is the art therapist's role to create a sacred safe space for exploration: guiding clients to let emotions and thoughts arise, pay attention, choose to put something on the paper and thus let it go. The levels of emotion awareness scale (LEAS) can be successfully measure changes in emotion awareness after engaging in art therapy (Lane, Quinlan, Schwartz, Walker, \& Zeitlin, 1990).

3. Acceptance of Emotion (AE). Once one becomes aware of emotions, one can engage in affect regulation by making choices about, attending, acknowledging and responding to those emotions (Gross, 2015). Emotion regulation (ER) refers to a collection of cognitive and behavioral strategies that effect when, for how long and with how much intensity an emotion is experienced and expressed. ER thus occurs after a process of valuation of an emotional response as good or bad (Gross, 2011). Acceptance of Emotion (AE) is an emotion regulations strategy in which individuals actively embrace and enact and attitude of being accepting, friendly, and nurturing toward their feelings (Weihs, Enright, \& Simmens, 2008). AE has been associated with experiencing less fear, catastrophic thoughts, avoidance behavior and better recovery from negative affect as compared to suppression (Gross \& John, 2003). Women coping with breast cancer who were less accepting of their emotions also reported greater distress than those who were more accepting (Politi, Enright, \& Weihs, 2007). AE can be seen as a mechanism of change by which art therapy enhances the individual's ability to concretely observe their 
emotions, obtain a reflective stance to their emotion expression, and feel positive feelings toward the art as an extension of their self, even if the emotion expressed is negative. Because of the process of externalization, along with the accepting and holding environment created in the art room, acceptance of emotion is well promoted through the art making process in art therapy. Acceptance of Emotion can be measured using the subscale of the Control of Feelings (COF) questionnaire (Politi, Enright, \& Weihs, 2007).

4. Reflective Stance. The capacity to take a reflective, or metacognitive stance toward one's thoughts and emotions is seen as an important process to prevent rumination and experiential avoidance (Feldman, Greeson, \& Senville, 2010; Fresco et al., 2007). Mindfulness is a metacognitive process that requires engagement and attentiveness along with an observational stance that is removed. Clients are taught to see thoughts, not as concrete reality, but just as thoughts, which come and go and therefore can be tolerated. One of the goals of mindfulness based therapies is to promote experiential acceptance (and thus negate experiential avoidance) by showing how mental states, albeit painful at times, can be non-harming and transient if engaged in a non-judgmental attitude of curiosity (Allen, 2012). This observational and reflective stance has been reported to assist the reduction of pain of chronic pain patients through enlivening and increasing optimism that can move away from the sense of being overwhelmed by pain (Fritsche, 2014). Reflective stance can be measured with the Mindful Attention Awareness Scale (Carlson \& Brown, 2005).

5. Perspective taking. The opportunity to create an image and then change it can be helpful in viewing reality from several points of view and thus offset the stage for reframing (Bandler \& Grinder, 1982). This ability to gain and then shift perspectives can be beneficial in adopting a more adaptive point of view (Czamanski-Cohen, 2012). Frequently, symptoms of depression and anxiety are accompanied by the sense of being stuck and engaging in the process of rumination, which is a maladaptive pattern of repetitively and passively focusing on the meanings, causes, and consequences of distress (Nolen-Hoeksema, Wisco, \& Lyubomirsky, 2008). Rumination, which is a key feature of depression, is characterized by perseverative thinking about one's sad affect and engagement in a thought loop that places the individual in a place of isolation, not engaged with the environment (Kashdan \& Rottenberg, 2010). Art making allows the opportunity to create a shift in perspective through engagement with internal experiences expressed in the art. This sets the stage for the client to proceed to visually change 
elements of this imagery in order to create cognitive, behavioral and eventually emotional shifts. Perspective taking can be measured using the Acceptance and Action Questionnaire (Bond et al., 2011).

6. Mentalization is a form of social cognition based on the ability to identify and reflect upon one's own emotions, and upon the emotions of other people that are distinct from one's own (Fonagy \& Bateman, 2006). In art therapy, mentalization is facilitated as: a) material is expressed on paper, thus we are dealing with conscious or near conscious mental content. b) Clients work through a mix of sensations, thoughts and feelings and create an integrated piece of art through which their emotions are identified. Through this process they achieve representational coherence and integration of emotional material upon which they can reflect. c) Art therapists may then reflect on the client's work through sharing their own observations of the art and thereby referring to content that is only slightly beyond the boundaries of the client's conscious thinking, as they relate to what is seen on the paper; d) the art therapy creates a transitional area of relatedness where thoughts and emotions can be "played with" through the art work, facilitating further identification and reflection on emotions Bateman \& Fonagy’s (2004).

The art product and art making process with the support of an art therapist can create this transitional space in which the art becomes an area of exploration of the emotional content in one's mind in a safe and non-threatening environment. The reflection of self in the art can be less threatening and may assist individuals who are threatened by intimate engagement to stay engaged in exploring their emotions (Springham, Findlay, Woods, \& Harris, 2012). In addition, art becomes a platform of communication through which the client examines her ability to be understood and express herself; the art becomes the object of attachment through which the client can “speak”, and gain practice in reflective functioning. Unlike many human beings, the art can tolerate such expression and can provide the sense of both being understood and being assisted in the ability to process difficult mental states. Mentalization can be measured with the Reflective Functioning Questionnaire (Fonagy et al., 2016).

7. Flow. Art making may enable individuals to engage in the process of "flow", which includes opportunities to challenge or stretch existing skills with clear goals that include feedback regarding progress (Csikszentmihalyi, 1997). The process of flow has been described as intense and focused concentration on what is being done in the present moment, the loss of 
reflective self-consciousness and a sense that one is in control, loss or change in sense of time and experience of the activity as rewarding so much that the process is as important as the end point or product. Art making has been hypothesized as an activity that helps obtain a sense of flow (Chilton, 2013). Flow can be measured successfully with the Flow State Scale (Jackson \& Marsh, 1996).

8. Working alliance is a psychoanalytic concept that involves the collaboration between the patient and therapist in the process of psychotherapy. The working alliance includes an agreement on treatment goals and tasks as well as a mutually positive emotional bond. We postulate that the triangular relationship between art therapist, client and art materials provide the opportunity to enhance the working alliance in a more rapid fashion than in traditional verbal psychotherapy. Furthermore, we believe that negative emotions can be channeled to the art materials, art making process and product leaving more "room” for positive emotional regard between client and therapist (Schaverien, 1987). The working alliance can be measured with the Working Alliance Inventory, short form revised (WAI-SR) (Falkenström, Hatcher, \& Holmqvist, 2015; Hatcher \& Gillaspy, 2006).

9. Experiencing. Our preverbal, pre-conceptual bodily sense of being in connection with the environment, the feeling of having a continuous stream of sensations, impressions, somatic events, reflexive awareness and cognitive meanings combine to produce our individual way of being in the world (Gendlin, 1962). Increasing levels of experiencing provides the opportunity to integrate bodily experiences with cognitive and emotional experiences. At somatic levels of experiencing, verbal expression is distant from feelings and personal involvement is absent. At the most integrated level of experiencing self-awareness is high and there is an integration of inner and outer experiences as references for thought and action. While the self-experiencing at this level is integrated and cohesive it is continuously flexible and open to change. Art making is especially conducive in contributing to the sense of experiencing as it can function as a bridge between inner and outer as well as preverbal and verbal experiences. The experiencing scales (Klein, Mathieu-Coughlan, \& Kiesler, 1986) can be used to measure experiencing.

10. Agency. Engaging in a task that requires some effort can increase one's sense of agency, as the effort required demands one's conscious attention, which in turn leads to the sense of agency in accomplishment (Damen, Dijksterhuis, \& van Baaren, 2014). An individual engaged in art making is an emotionally engaged agent who will be able to use the art product to reflect 
upon their emotions. Qualitative studies have shown that women coping with breast cancer report that regaining a sense of self and improved self-efficacy were benefits of art therapy (Collie et al., 2006; DeCristofaro, 2007; Devlin, 2006; Forzoni, Perez, Martignetti, \& Crispino, 2010; Lipson, 2011). Self -efficacy and agency are related concepts. Self-efficacy is an individual's belief in their ability to deal effectively with a particular task which effect's agencythe capacity to coordinate sills, motivation and emotion to achieve the goal (Bandura, 1982). Art making facilitates an increase sense of success and accomplishment that can occur after art making in a supportive relationship, and can later be translated in to coping in so called "real life”. Agency can be measured using the agency subscale of the Snyder Hope Scale (SHS) (Babyak, Snyder, \& Yoshinobu, 1993; Snyder, 1995).

\section{Valuation. One assumption of our model is that individuals act out of different} motivations based on an assessment of whether any given behavior, feeling or thought is good or bad for them. Art making gives an individual the opportunity to pause and valuate their motivations. Because art making in an art therapy framework is a self-generated activity, which occurs in a supportive and safe environment, clients have the opportunity to create images that may help to access the motivations that parallel their valuation processes. Demoralization occurs when a person's motivations are curtailed due to a sense of subjective incompetence. By facilitating valuation, art therapy is likely to help with re-moralization (Gross, 2015). Valuation can be measured by using the Affect Valuation Index (AVI)(Tsai, Knutson, \& Fung, 2006). 12. Meaning making. This occurs as an ongoing process of narrative, which is accompanied by feelings of integration fulfillment, having a goal or purpose for life and seeing oneself as unique and valuable (Lee, Cohen, Edgar, Laizner, \& Gagnon, 2006). Art therapy lends itself well to the process of meaning making and finding purpose. The process of creating a unique art product and finding one's own visual language contributes to seeing oneself as unique or valuable. As people create unique, emotionally expressive imagery, they create a narrative of their own purpose and uniqueness, and can use the art product as a mirror of self-reflection and emotional authenticity (Czamanski-Cohen, 2012). Meaning making can be measured by using the Schedule for Meaning in Life Evaluation (SMiLE) (Fegg, Kramer, Bausewein, \& Borasio, 2007).

13. Sense of Coherence (SOC). Sense of coherence is a resource that enables people to reflect about their external and internal resources and to promote effective coping by finding solutions, 
and resolve tension in a health promoting manner. It is part of the salutogenic model of health by Antonovsky (Eriksson \& Lindström, 2006). SOC has been shown to be positively related to positive mental health in face of adversity, such as cancer (Sarenmalm, Browall, Persson, FallDickson, \& Gaston-Johansson, 2013; Shor, Grinstein-Cohen, Reinshtein, Liberman, \& Delbar, 2014; Winger, Adams, \& Mosher, 2015), as well as being improved as a result of psychosocial interventions (Casellas-Grau, Font, \& Vives, 2014). Achieving representational coherence and integration occurs as a natural process of creating a coherent piece of art. Sense of Coherence can be measured using the sense of coherence scale (SOC) (Eriksson \& Lindström, 2006). 